\title{
TEACHING BUSINESS PROCESS MANAGEMENT: IMPROVING THE PROCESS OF PROCESS MODELLING COURSE
}

\author{
Martin Hrabala* \\ Tomas Bata University in Zlín, Zlín, Czech Republic \\ Michaela Opletalováb \\ Tomas Bata University in Zlín, Zlín, Czech Republic \\ David Tučekc \\ Tomas Bata University in Zlín, Zlín, Czech Republic
}

Process approach is a part of many organizations' management systems. Process oriented organizations focus on value added processes, their management, performance measurement, improvement and automation. However, in many higher education institutions is not process management implemented and its teaching does not always correspond with business needs and practice. This paper deals with the latter side of process management in higher education - course of process management held at Faculty of management and economics of Tomas Bata University in Zlín. The main purpose of the paper is to present the results of the research among Czech universities and their approach to BPM education and a case study of process management course and its improvement at Faculty of Management and Economics at Tomas Bata University in Zlín. To improve the course, the very aspects of process management such as customer focus or performance measurement were applied. The performed action research is then described in form of the case study.

Key words: Active learning, Business process management, Higher education, Process improvement, Process modelling

\section{INTRODUCTION}

Business Process Management (BPM), whether as a managerial discipline or technology competence, stays one of the priorities of companies. According to APQC (2016), process management is the priority for $86,1 \%$ of companies before performance management, change management or big data. Therefore, BPM can belong among key competencies for future managers, process owners, business analysts, industrial engineers or IT specialists. Knowledge and training of other workers facilitates and accelerates BPM implementation. BPM can be understood as a holistic managerial discipline which emphasizes processes as key organizational assets. To distinguish between BPM and its technology support in the form of software applications we will address to managerial discipline as BPM and to its technical means as Business Process Management Systems or Suits (BPMS). As indicated, BPM is the managerial discipline which evolved from Total Quality
Management (TQM), Business Process Reengineering, Lean, and today includes variety of methods and techniques (Jeston and Nelis, 2008). Organizational process is a set of interrelated activities which together aim to achieve certain goal. Every process should therefore have its customer who demands certain value. In the late 1980s and especially 90s organizations started their reengineering programs which should radically improve performance and break organizational silos within processes. This era is connected with Hammer together with Davenport who described the practice of reengineering and developed its methodology (Hammer, 1990; Davenport and Short, 1990). However, improvements were often disputable and projects' failure rate was high. According to Smith and Fingar (2007), instead of reengineering organizations needed continuous improvement of their processes. Thus, third wave of process management started - after waves of TQM and BPR. Today, we can see variety of BPM projects in industries, services or non-profit sector. Whether they are using Lean, Six Sigma or BPR, 
they are always process and customer focused. All these aspects are indicators of the importance of BPM specialists in modern organizations. Thus, their effective education and training is needed through their studies in a university.

\section{PROCESS MANAGEMENT IN HIGHER EDUCATION}

Little different situation is in the higher education. It is obvious that many universities and business schools are structured according to functions such as finance, marketing, management, logistics etc. Similarly are structured also study programs and students cannot appropriately interconnect ideas and knowledge. Also these programs and their graduates do not correspond with requirements of business, information technology development and the idea of flat organizations (Walker and Black, 2000). Although universities, especially these with economic and management study programs, partly recognize and teach BPM but they remain in functional silos themselves (Hars, 2002). The functional structure results in the lack of cross-functionality and process awareness of students (Seethamraju, 2012). In literature can be found suggestions how to apply BPR to higher education. According to Davis and Mehta (1997) there are following steps of BPR:

- creating adequate culture,

- set up BPR team and steering committee,

- complete feasibility study,

- developing vision,

- training the team,

- informing everyone in the organization about BPR efforts,

- analysing work to be reengineered,

- selecting and training staff in the reengineered process,

- training leaders in new roles.

Processes suitable for BPR can be, according to these authors, e.g. accreditation, curriculum design, faculty development and evaluation, student grading and evaluation, research etc. Abdous (2011) proposes the practice of BPR in the following steps:

- Initiation

- Analysis

- Reengineering

- Implementation

- Evaluation.

But it is rather simple application of Hammer's and Champy's methodology.
Critical success factors of BPR in higher education are: understanding a context, shared vision, and involvement of management and leveraging of information technologies (Ibid.). According to Ahmad, Francis and Zairi (2007) is stressed teamwork and quality oriented culture, quality management system, rewards, change management, less bureaucratic and participative style, role of information technologies, project management and adequate financial results the main critical success factors of BPR. Process description can be valuable for multiple reasons. According to [12], process definition, design and description are relevant for accreditation, or in case of merges of several schools. Process management also becomes one of the key components of management system of tertiary institutions in the Czech Republic. According to Individual National Project EFIN, process management should be part of institutions' maturity model and can be roadmap for next improvement of performance. (Tuček and Basl, 2011) According to Walker and Black (2000) is defined process oriented undergraduate curricula derived from generic high-level processes which can be found in most of organizations: acquisition of resources and payment, conversion or service provision, and acquisition of customers and revenue collection. Subjects are then structured into courses of acquisition of capital resources, human resources acquisition, conversion and service, sales / collection / customer service, and organizational performance measurement and management. Processes are therefore integrative theme for functional knowledge (e.g. finance) and skills (e.g. communication).

\section{TEACHING PROCESS MODELLING AND MANAGEMENT}

Although business schools are mostly organized according to functions, they often provide process management courses to some extent. Bandara et al. (2010) provided case studies of five universities - Bentley University, Georgia State University, Queensland University of Technology, University of Pretoria and University of Vienna. In most cases they provide courses or programs of BPM and related disciplines such as Industrial Engineering, Six Sigma, Business analysis etc. Courses mostly respect both managerial and technology aspects of BPM. Students are introduced to BPM, BPR, Lean, automation and workflow techniques and can 
analyse and model processes. Graduates then know BPMS such as ARIS, Bizagi, or Inno8 and can utilize it together with knowledge of Enterprise Resource Planning systems (ERP). But even BPM courses with long tradition lack pedagogical resources - both materials in form of textbooks and case studies, and instructors who are trained and experienced. One of the developed programmes provides Queensland University of Technology. Lectures are complemented by practical workshops in PC labs where students can train process modelling in ARIS and YAWL. Students also conduct assignments in form of projects and go through required readings per week. After a course is gathered students' feedback. (Recker and Rosemann, 2009) Another example is Tomas Bata University in Zlín which started with process modelling in 2010. The optional subject Computer Support of Business Processes was parallel with mandatory subject Reengineering. The former provided training in process modelling with ARIS Business Designer, the latter general theory of BPR and BPM. (Tučková and Tuček, 2010)

\section{METHODOLOGY}

Prevalent method used in this paper is the case study and the action research. Case study is a method designed to particular in-depth study of a specific case in certain context. Action research is then intervention method to improve specific process and analyse the results of the action. (Pickard, 2013). In this paper, we describe the case study of BPM education at the Faculty of Management and Economics at Tomas Bata University in Zlín together with its improvement. The case study focuses on the innovation of Business Process Management course at the faculty. This course was at first concerned only with theoretical concepts of Business Process Reengineering (BPR), later it was merged with optional course Computer Support of Enterprise Processes. This connection lead to a new concept of teaching - lectures are still prevalently concerned with theoretical aspects of BPM and BPR but seminars are focused on practical training of process modelling in specialized software application ARIS.

The course is mandatory for students in these study programmes: Enterprise economics, Marketing and management, and Industrial Engineering. This is especially challenging because students have different background and demands. The action research was conducted as an application of process improvement on the education process itself. After process analysis of BPM course we performed survey among students which can be viewed as process customers and collected data about their expectations before and feedback after absolving the course. Analysis of this feedback provided insight into the students'- customers' value and suggestions for improvement were developed.

The course takes place in winter semester. The improvement project started in the academic year 2014/2015 and continued in 2015/2016. The procedure was as follows:

- Introducing the subject and gathering expectations from students (voice of customer)

- Running the course

- Gathering and analysis of students' feedback on the course

- Suggesting improvements and their implementation with the subject's guarantee

- Running the improved course

- Gathering and analysis of students' feedback on the course to evaluate the improvement

The course was innovated with regard to students' expectations which are considered as customers of educational process and which could be slightly different from expectations of labour market and employers, but also with regard to current trends in BPM and its education. Requirements of employers on graduates' competencies were also taken into consideration. Currently, the labour market places great emphasis on the practical skills of graduates, no longer so much on their knowledge. In connection with this trend, it was decided to innovate BPM course as a course, which is the cornerstone of effective management skills, analytical skills and skills of continuous improvement in organization of any type. To support innovative teaching of BPM course, research was conducted whose aim was to determine the current state of BPM teaching level at universities in the Czech Republic. As part of this research were interviewed 33 respondents public, private and state tertiary institutions. The questionnaire was aimed to determine whether and how these schools are preparing students in the field of Business Process Management. Respondents were selected according to the focus of taught subjects: economics, business economics, management and business management. So fields where is the premise of teaching BPM 
with respect to future employability of graduates in the labour market. The questionnaire was completed by 17 respondents $(51 \%$ of interviewed respondents). The results showed that 10 respondents have BPM course directly incorporated into study program and 5 respondents teach BPM topic in some main courses. Only 2 respondents answered that they do not teach BPM topic at all. These 2 respondents stated that they do not include the teaching of any element of BPM as well as their school has not mapped own processes and does not practice BPM at the level of their management. Other respondents classified to the teaching BPM theory, process analysis and improvement, process controlling and economic evaluation of processes. Conversely, the teaching of process modelling and/or process simulation in special software is very infrequent.Some respondents also try to approach the BPM teaching comprehensively and systematically pick on it for another subject as logistics, information systems, business economics or production management. Research has found no relationship between the type of university (public, state, and private), size of school or school focus (economic, technic) and level of standard of BPM education. The research also showed that the overall level of BPM teaching at Czech universities is low to moderate. Business Process Management as part of job of middle and senior manager, project manager, process engineer or leader should be seen as one of the basic field with a maximum practical benefit to students of economic and technical fields.

\section{RESULTS}

Based on the above facts it was decided to innovate the course towards practical skills. Original course of BPM was merely theoretical and students lacked practical skills. After its merge with optional course Computer Support of Enterprise Processes it gained the practical seminars with training in computer lab but the students' feedback indicated discontinuities between content of lectures, seminars and assigned seminar works. Moreover, seminar work was above the skills of students who have not yet developed proper competencies in process redesign and also didn't manage to convince entrepreneurs to provide them an opportunity to lead a redesign effort. At the end of winter semester of 2014 the feedback on original course was gathered and analysed, suggestions for im- provement were developed and implemented for next academic year. Final evaluation from students of original course was 3.4 points out of five and standard deviation 0.9 . Only $30 \%$ of students stated that they plan to utilize process modelling in their master thesis but $55 \%$ of them want to use it during their career. There were no significant distinctions between students from different fields. New course design comprised of changed seminars curriculum and seminar work requirements. The goals of the course innovation were to promote the process thinking across several fields of study, their cross-functional cooperation, and competence in teamwork, process design and modelling. These goals were determined new form of the course and its process. At first, requirements on seminar works were changed. Because process orientation promotes teamwork and cross-functionality, instead of individual work on process redesign in specific organization, students form own teams and design their own processes in virtual companies. Among themes for the assignment were e.g. supply chain management, sales of goods, technological preparation of production, organizing marketing campaigns, management of hotel etc. On the seminars, students become acquainted with tools such as SIPOC and process flowchart, later they adopted methodology of ARIS and created models according to case studies. Finally, each team developed SIPOC and process models in ARIS for their assigned projects and presented it.

Seminars were conducted in modern interactive way, especially in the teamwork part of the course. This interactive learning should promote cross-functional collaboration in the design phase of BPM. The aim of this teaching method was to prepare the students for interdisciplinary teamwork, communication, other views on one issue creating processes and procedures and independent thinking and decision making. The direction in which the course was upgraded is considered the most modern method of learning today. Students are taught interactively acquainted with the field and at the context of their own experience through playing games and independent work they have the greatest chance to memorize everything and practically use it in the future. 


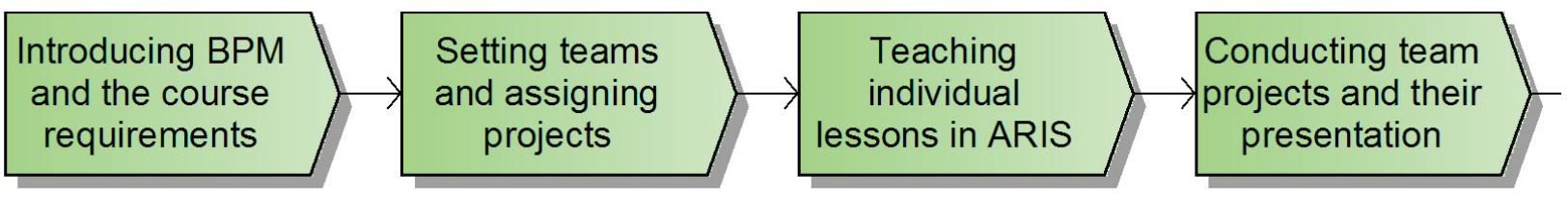

Figure 1: Process of the BPM course (own processing)

\section{The redesign course description}

After the students' registration to the course and the start of semester, the course begin with introduction of BPM as a managerial discipline, requirements to complete the course and software application ARIS. After the introduction, students form teams and choose project topic which they conduct through the run of the course. Students had the task to develop business model of a virtual organization. They should identify the voice of a customer, define a product, vision and mission. On the basis of their strategy students designed value chain, and its main, management and support processes. Finally, students modelled these processes.Before students start with modelling in ARIS, they became acquainted with SIPOC and simple flowchart diagrams which they apply within their team projects on flipcharts. Later start lessons in ARIS: orientation in the application and structure of the database, meaning of the individual models and symbols, creating value-added chain diagrams (VAC), function allocation diagrams (FAD), event-driven process chain (EPC) and key performance indicators diagram (KPI). Each type of model is explained in the context of business. VAC diagrams are used to model value chains and processes with subprocesses. FAD and KPI diagrams are connected to the theme of process context, management and performance measurement. EPC express the detailed process description. Students learn how to systematically build a complex model which is composed of interlinked diagrams which describe different perspectives on a business and its processes. Figure 2 shows the structure of a process model and its decomposition. The course continues with teamwork on the assigned projects where student teams work on their own process models which they finally present to the whole class. The project should contain the simple description of the organization and its context, process model composed of SIPOC, VAC, FAD, KPI and EPC diagrams together with an organization charts. In the end of the semester, students' knowledge is verified via a test in ARIS. After passing the test, students may proceed to the final evaluation of the course. After seminars, a feedback on the course is gathered and analysed. The conception and structure of the BPM course is shown in the table 1.

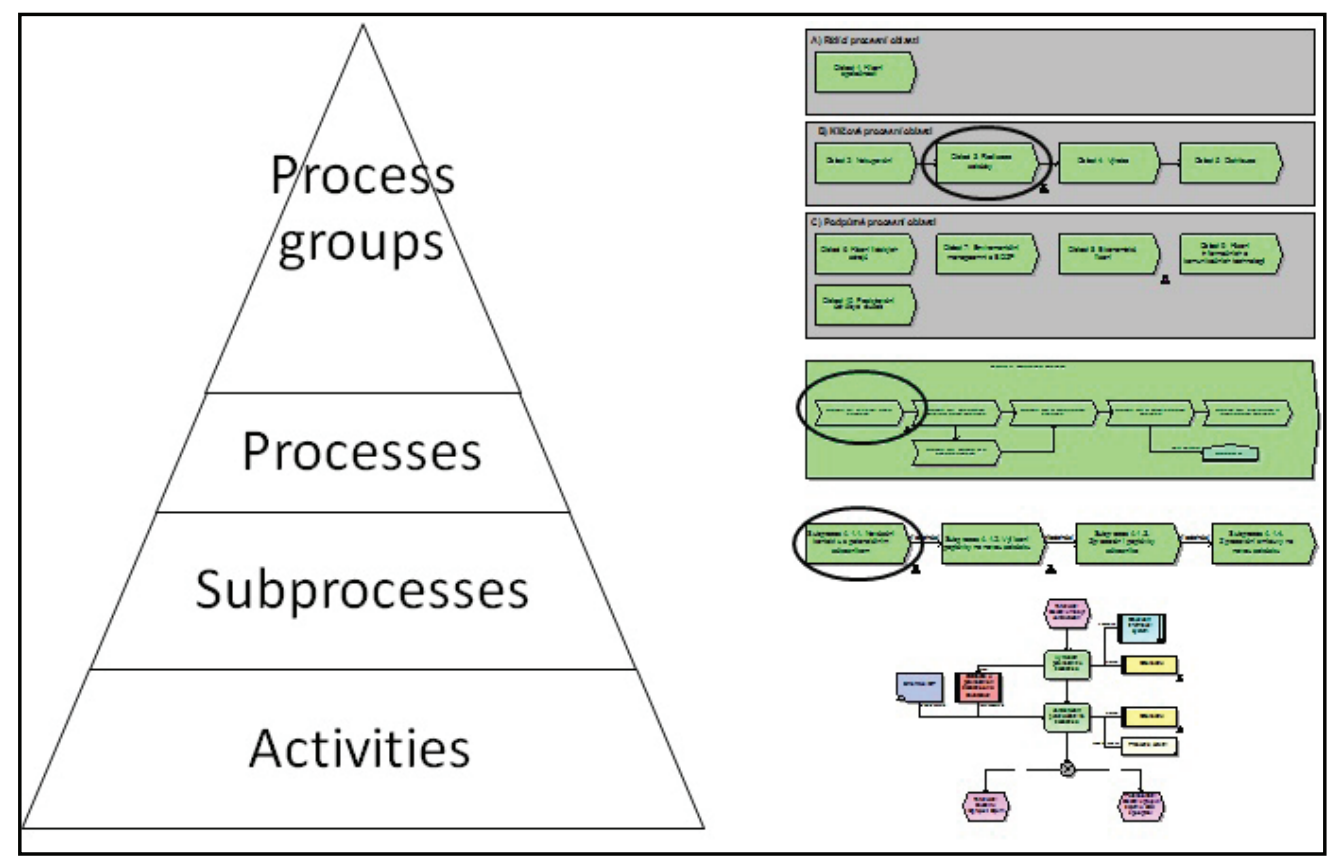

Figure 2: Process model structure and its hierarchy (own processing) 
Table 1: BPM course outline (own processing)

\begin{tabular}{|c|c|}
\hline Goal of the course & $\begin{array}{l}\text { Student understands and can apply concepts of BPM and BPR } \\
\text { Student can create various process models in ARIS }\end{array}$ \\
\hline Methodology and tools & $\begin{array}{l}\text { DMAIC methodology } \\
\text { ARIS method (ARIS Designer and Express) }\end{array}$ \\
\hline Materials & $\begin{array}{l}\text { Presentations } \\
\text { Case studies } \\
\text { ARIS guidebook }\end{array}$ \\
\hline Tasks & $\begin{array}{l}\text { Process modelling in ARIS } \\
\text { Team project }\end{array}$ \\
\hline Content of seminars & $\begin{array}{l}\text { 1. Introduction - the course and BPM, assigning team projects } \\
\text { 2. Development of strategy and overview process map } \\
\text { 3. SIPOC and flowcharts - teamwork, setting up repositories } \\
\text { 4. Value chains - theory, and modelling VAC } \\
\text { 5. Performance measurement - theory, modelling FAD and KPIs } \\
\text { 6. Process analysis - modelling EPC } \\
\text { 7. Organization structures - theory, modelling organization charts } \\
\text { 8. Summary of modelling - modelling complex case study } \\
\text { 9. Teamwork - conducting team projects } \\
\text { 10.Presentation of team projects } \\
\text { 11.Test - verification of knowledge }\end{array}$ \\
\hline
\end{tabular}

\section{Students' feedback on the redesign course}

After the end of the semester we analysed students' feedback on the new course. The rate of questionnaires return was much lower only 18 students responded out of 110 . Again, we tracked students' satisfaction was 4.1 out of 5 points with standard deviation 1.1. There were higher disproportions between the satisfaction rates of different fields of study. However, only one student declared that he is willing to use process modelling in master thesis, three do not plan to use it and fourteen do not know yet. But five of them plan to utilize the BPM knowledge in their practice after graduation. The reason why not to use BPM are mainly different fields of interest or the fact, that student does not have exact idea what topic of thesis to choose or which profession does he aspire on. Among the highest ranked knowledge and skills which students gained during the course were stated process management and teamwork, followed by project management, computer literacy, and analytical and systemic thinking. On the contrary, the less rated was economic knowledge. The very software tool ARIS Designer was accepted positively. But it would be beneficial to try another BPMS, compare them and try to trans- fer skills among various software applications. In the most cases, students positively assess the teamwork projects as they helped them to understand the concept of BPM, and perspectives of other functions (such as industrial engineering, marketing, finance, management etc.).

\section{DISCUSSION}

Business Process Management course is set up to reflect 6 fundamental pillars of process orientation: customer focus, teamwork, crossfunctional processes, analytic and systemic thinking, and especially computer literacy especially in ARIS software application. The course is prevalently focused on the design phase of the process lifecycle. It is stressed that the design is determined by the strategy and designed models must be implemented and their performance measured and continuously improved.

To clarify the relations between process and project management, DMAIC (define, measure, analyse, improve, control) methodology is used as a means of process lifecycle description and management.Students focus on the design phase within the course and can relate phases of measure while methods used in other phases are presented in different courses according to 
the field of study. Among them we can mention Lean, Activity Based Costing, simulations, linear programming etc. Through such mental model, student can orient themselves in various management and economic disciplines in relation to a business process. The only obstacle in maximizing the positive impact of innovation the teaching of the course were students from different fields of study. Students come from different focus areas and for some of them, this topic is more tangible than for others. Some students consider the topic of BPM as very abstract and generally not engaged by their field of study. All students are taught together in one block of seminars. Effective innovation that would allow teaching more focused on students and adapt on their pace and knowledge could be separate students to the various seminars based on their field of study. Lectures could stay for all students together and seminars will be separated. This amendment would allow teacher better work with students even more and adapt to their future work and practice.

\section{CONCLUSIONS}

After the first innovation of the BPM course towards the interactive learning and discussion it was shown that students accepted this innovation very positively. Especially personal response and a change in students' understanding of the issues showed that the changes were step in the right way. Teachers can compare between different academic years and changes were considerable. Students easily understand the issues, they associate the issue with practical problems better and they learn how to think over the discussed topics. Based on experience, the course will leave in this form for the next academic year. There will be only few little changes in schedule of seminars to better match the pace and knowledge of students who come from different disciplines. Since we consider this course to be extremely beneficial for students and their future practice, it would be appropriate to think about extending this philosophy of education at other colleges, where is BPM fully or marginally engaged.

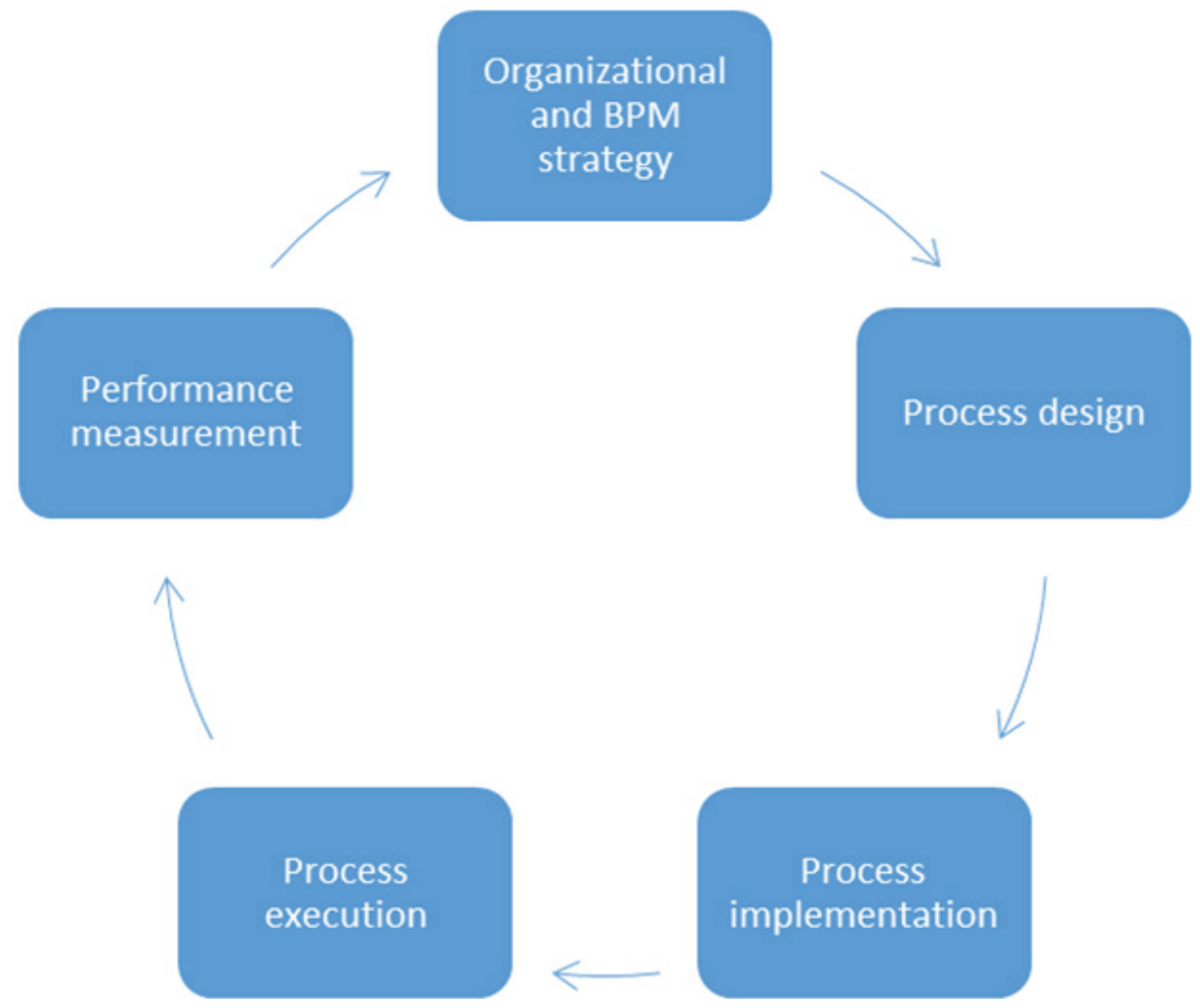

Figure 3: Process lifecycle (own processing) 
This course is crucial for understanding the organization management and function and students should be prepared on these issues. Every day in practice we encounter a lack of understanding of concepts such as strategy, vision, mission, business management or process. These concepts should be known by each manager and owner of the organization. They should be able practice methodologies associated with these concepts. Students of economic and technical field should be those who will be hold management positions in organizations. People at these functions have to create plans, make right choices and decisions and lead organization to success and profit. They should be able to establish long-term plans for achieving key goals and fulfil the vision and mission of the organization. They should also be able to communicate strategy and corporate culture, analyse processes and implement changes. In all of these basic daily activities could be process management very helpful and it can become an effective tool and a means to control. Interactive teaching approach basic skills such as communication, teamwork, negotiation and presentation of student work and results of his team. These practical skills are invaluable to a student in any job in any position and also in everyday life.Changes in attitude of students, their enthusiasm and understanding of the issue and the overall concept of teaching BPM could convince more universities and colleges to apply the same or similar approach.

\section{ACKNOWLEDGMENT}

The authors are thankful to the Internal Grant Agency of FaME TBU No. IGA/FaME/2015/043 (Management and software support of internal processes in hospitals in Czech Republic) for financial support to carry out this research.

\section{REFERENCES}

1) $A P Q C, 2016$. Process and Performance Management, https://www.apqc.org/knowledge-base/download/363319/K06479 2016_PPM_Priorities_Survey_Summary.pdf (viewed at $\overline{9}$ Apr. 2016)

2) Abdous M., 2011. Towards a framework for business process reengineering in higher education, Journal of Higher Education Policy and Management, (33)4, pp. 427-433.

3) Ahmad H., Francis A. and Zairi M., 2007. Business process reengineering: Critical success factors in higher education, Business Process Management Journal, (13)3, pp. 451-469.

4) Bandara, W. vom et al., 2010. Business Process Management Education in Academia: Status, Challenges, and Recommendations, Communication of the Association for the Information Systems, (21), pp. 744-776.

5) Brennan L. and Austin W., 2003. Addressing the Need for Management Processes for Higher Education Accreditation, Innovative Higher Education, (28)1, pp. 49-62.

6) Davenport T. H. and Short J. E., 1990. The New Industrial Engineering: Information Technology and Business Process Redesign, Sloan Management Review, (31)4, pp. 11-27.

7) Davis J. and Mehta K., 1997. Reengineering a School of Business of the Future: A Mission/Vision Model for Higher Education in Transformational Times, SAM Advanced Management Journal, (62)2, pp. 8-15.

8) Hammer M., 1990. Reengineering Work: Don't Automate, Obliterate, Harvard Business Review, July-August, pp. 104-112.

9) Hars A., 2002. Using BPR Tools in Business Process Education. In A. W. Scheer, F. Abolhassan, W. Jost and M. Kirchmer (Eds.), Business Process Excellence: ARIS in Practice, Berlin: Springer, pp. 175-186.

10) Jeston J. and Nelis J., 2008. Business process management: Practical guidelines to successful implementations, Amsterdam: Elsevier/Butterworth-Heinemann.

11) Recker J. and Rosemann M., 2009. Teaching Business Process Modelling: Experiences and Recommendations, Communication of the Association for the Information Systems, (25), pp. 1-16. 
12) Seethamraju R., 2012. Business process management: a missing link in business education, Business Process Management Journal, (18)3,pp. 532-547.

13) Smith H. and Fingar P., 2007. Business process management: the third wave. [4th Anniversary ed.]. Tampa, Fla: Meghan-Kiffer Press.

14) Tuček D. and Basl J., 2011. Using BPM Principles to Increase the Efficiency of Processes in Higher Education in the CR. In: Proceedings of the $2^{\text {th }}$ International Conference on Education and Educational Technologies. Greece, Corfu: World Scientific and Engineering Academy and Society (WSEAS/ NAUN), pp. 47-51.
15) Tučková Z. and Tuček D., 2010. Increasing knowledge by teaching of modern BPM systems. In: Latest Trends on Engineering Education. Greece, Corfu: World Scientific and Engineering Academy and Society (WSEAS), pp. 487-492.

16) Walker K. B. and Black E. L., 2000. Reengineering the undergraduate business core curriculum: aligning business schools with business for improved performance, Business Process Management Journal, (6)3, pp. 194-213.

Paper sent to revision: 24.10.2016

Paper ready for publication: 29.11.2016. 